\title{
COVID-19, Ebola virus disease and the community
}

The Democratic Republic of the Congo (DRC) declared the end of its 10th Ebola virus disease (EVD) outbreak on 25 June 2020. The outbreak was declared in North Kivu on 1 August 2018, and by the time it ended there had been 3480 cases and 2287 deaths. ${ }^{[1]}$ This outbreak was one of the worst experienced since the 2014 - 2016 EVD outbreak in West Africa and occurred in the context of a complex humanitarian crisis. In spite of this, the response in the first weeks of August was noted to have been the fastest, the best equipped and the best funded in the history of EVD response. ${ }^{[2]}$ So why did this outbreak in North Kivu and Ituri, DRC, not only persist but spread widely, crossing a national border into Uganda and reaching Goma, the capital of North Kivu? To try to answer these questions, the World Health Organization (WHO) despatched members of the Independent Oversight Committee, who are part of the WHO Health Emergencies Programme, to carry out a detailed examination of what went wrong in response to and preparedness for this devastating outbreak. The key to their findings was that there were two primary barriers that limited access to affected communities. The first was security, in particular attacks on communities and response workers by armed groups, which at one stage led to complete shut-down of the response. The second barrier, described as arguably more important by the committee, was lack of community acceptance of response. EVD responses are intrusive to communities, affecting many aspects of daily life, including burial of the dead and the rituals surrounding this, which have profound and personal significance. Their main message was that to be effective, a response has to 'first be able to elicit the views and concerns of affected communities to adapt interventions to community needs'. All this centres on trust and transparency.

Why am I talking about an EVD outbreak in a distant central African country? South Africa (SA) is currently almost certainly heading towards a third wave of COVID-19, and our glacial vaccine roll-out will not protect most of us. In the face of this potential third wave, the government sold 1.5 million doses of the AstraZeneca vaccine acquired from India to the African Union. Before the announcement that this was a fait accompli was made, an article published in Spotlight asked whether the government had a moral obligation to roll out the AstraZeneca vaccine. ${ }^{[3]}$ The actual sale of these vaccines now makes this question irrelevant. However, there were interesting revelations in the article, not least around the total lack of transparency on the part of government around its decisions regarding vaccine use and roll-out. In the article, lawyer and ethicist Ciara Staunton points out that science is not the only factor that governments take into account when making healthcare decisions politics, economics, cost and even individual rights all play a role, particularly where resources are scarce. As she says, 'Trust is key'. Governments have a responsibility to explain to the public why they are making these decisions. The SA government and Ministry of Health have engaged various experts to sit on ministerial advisory committees (MACs) since the start of the COVID-19 pandemic, and have a specific vaccine MAC. This MAC, chaired by Barry Schoub, prepares advisories, recommendations on issues that become the property of the health minister, who is free to accept or reject them. But again, the issue is around trust. None of the advisories around the decision to shelve the AstraZeneca vaccine have been made public. Additionally, the vaccine MAC does not include any representatives from civil society. In fact, Barry Schoub stated that he doesn't believe it is appropriate to include lay people on the committee. 'The MAC is a body of experts, of scientific and medical experts, who look at the scientific aspects, and not the sociological and anthropological and those kinds of issues [sic],' he said. 'There aren't any lay people on the committee at all. I don't think it is appropriate'

These statements are quite astonishing. So far, COVID-19 has affected more than 1.5 million people in SA and cost $~ 8.2 \%$ of the gross domestic product (ZAR389 billion) in 2020. ${ }^{[4]}$ The very fabric of people's lives has been completely disrupted. Funerals, which are a very important cultural event in southern Africa, are known to be potential spreading events and are currently limited to attendance of 50 people. ${ }^{[5]}$ However, as I write this, the National Coronavirus Command Council is apparently discussing allowing increased numbers for church and religious gatherings over the Easter weekend. ${ }^{[6]}$ Schoub's position that lay people are not appropriate on the MAC is at the least astounding and at the worst, dangerous. One of the most important lessons learnt by those whose work involves responding to outbreaks and emergencies is that engaging the trust of affected communities is crucial to the success of any response. Sociologists and anthropologists are integral parts of the response to EVD and other outbreaks elsewhere on the continent, where cultural norms and practices may play a role in disease transmission. Community action groups, religious leaders and youth groups are all actively engaged, along with the scientific, epidemiological and medical personnel on the ground. As the activism that was necessary to get our HIV/AIDS response off the ground showed all too well, you ignore the role of the community at your peril.

\section{Bridget Farham \\ Editor \\ ugqirha@iafrica.com}

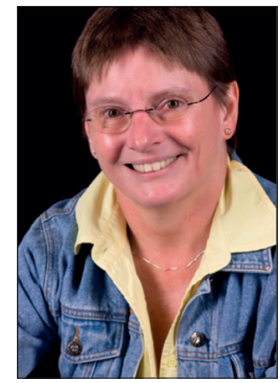

1. World Health Organization. 10th Ebola outbreak in Democratic Republic of the Congo declared over vigilance against flare-ups and support for survivors must continue. 25 June 2020. https://www.who. int/news/item/25-06-2020-10th-ebola-outbreak-in-the-democratic-republic-of-the-congo-declaredover-vigilance-against-flare-ups-and-support-for-survivors-must-continue (accessed 24 March 2021). Independent Oversight and Advisory Committee for the WHO Health Emergencies Programme. From 'never again' to the 'new normal': What does the 2018 - 2019 Ebola outbreak in the Democratic Republic of the Congo tell us about the state of the global epidemic and pandemic preparedness and response? World Healt Orgaization, 2019. hups/tapps who pdf (accessed 24 March 2021).

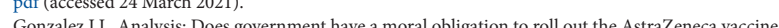
Spotight, 19 Mas 2021 Spolight, 19 An have-a-moral-obligation-to-roll-out-the-astrazeneca-vaccine/ (accessed 24 March 2021.

Van den Heever A, Valodia I, Lucy A, Veller M, Madhi S, Venter F. Towards herd immunity from Covid-19: Costing a vaccine strategy for South Africa. Daily Maverick, 7 January 2021. https://www. dailymaverick.co.za/article/2021-01-07-towards-herd-immunity-from-covid-19-costing-a-vaccinestrategy-for-south-africa/ (accessed 24 March 2021).

5. Dzinamarira Z, Musuka G. When culture, traditions and public health clash: A paradigm shift urgently needed to stem the spread of COVID-19 in Zimbabwe. S Afr Med J 2021;111(4):279. https://doi. org/10.7196/SAMJ.2021.v11114.15637

6. Hunter $\mathrm{Q}$, du Plesis C. Coronavirus Command Council advised to move SA to level 2 as it mulls over hiking church gatherings. News24, 24 March 2021. https://www.news24.com/news24/SouthAfrica/ News/coronavirus-command-council-advised-to-move-sa-to-level-2-as-it-mulls-over-hikingchurch-gatherings-20210324 (accessed 24 March 2021).

S Afr Med J. Published online 25 March 2021. https://doi.org/10.7196/SAMJ.2021. v111i5.15721 